(2) Open Access Full Text Article

\title{
Arterial Thrombosis in an Asymptomatic COVID-19 Complicated by Malignant Middle Cerebral Artery Syndrome: A Case Report and Literature Review
}

\author{
Ali A Alzahrani (iD \\ Hissah Al Abdulsalam (D) ${ }^{2}$ \\ Hussein Al-Sakkaf (D) ${ }^{3}$ \\ Ayat Yousef $\left(D^{3}\right.$ \\ Fahad B Albadr (D) ${ }^{3}$ \\ 'College of Medicine, King Saud \\ University, Riyadh, Saudi Arabia; ${ }^{2}$ Division \\ of Neurosurgery, College of Medicine, \\ King Saud University, Riyadh, Saudi \\ Arabia; ${ }^{3}$ Department of Radiology, \\ College of Medicine, King Saud \\ University, Riyadh, Saudi Arabia
}

\begin{abstract}
Coronavirus disease 2019 (COVID-19) is a severe infectious respiratory disease caused by the novel coronavirus known as severe acute respiratory syndrome coronavirus 2 (SARS-CoV-2). Multiple studies in the literature highlight the association between COVID19 and stroke. We report a case of acute ischemic stroke in a COVID-19 patient without displaying symptoms of active COVID-19 infection or risk factors for stroke with further review of the literature. The patient's recovery was complicated by hemorrhagic stroke, which resulted in death. Acute ischemic strokes are one of the challenging complications of COVID-19 infection. Initial rapid assessment and management are crucial in optimizing the outcomes on these patients. Nevertheless, wearing appropriate PPE should be instituted while providing adequate care.
\end{abstract}

Keywords: ischemic stroke, COVID-19, SARS-CoV-2, carotid artery thrombosis, infection, case report

\section{Introduction}

Coronavirus disease 2019 (COVID-19) is characterized by severe acute respiratory syndrome, and the global COVID-19 pandemic has resulted in more than 2,800,000 deaths worldwide. ${ }^{1}$ Cardiovascular and cerebrovascular complications are associated with mortality in patients with COVID-19 infection, indicating a proposed risk of coagulopathy leading to thromboembolic events. ${ }^{2-4}$ Most COVID-19 patients present with constitutional and respiratory symptoms; less commonly, they may present with atypical neurological manifestations. ${ }^{5}$ However, numerous recent studies in the literature spot the light on the association between COVID-19 and stroke. To improve our understanding of the associated cerebrovascular events in the setting of COVID-19 infection, we present a unique case of a patient with acute ischemic stroke who tested positive for COVID-19. The patient was asymptomatic and had no medical history or risk factors for stroke.

\section{Case Presentation}

College of Medicine, King Saud University, P.O. Box 13265, Riyadh, 8101, Saudi Arabia

Tel +966508622244

Email ali.a.h.alzahrani@gmail.com
A 51-year-old male presented with more than 5 hours of right-sided weakness and aphasia. His brother took him to a local hospital after a sudden fall; then, the patient was taken by EMS to our emergency department. Before admission, he was healthy with 
no reported respiratory symptoms. A nasopharyngeal swab for COVID-19 was performed on arrival for screening. He was afebrile, with no specific medical history, medication, or obvious stroke risk factors. Upon examination, the patient was awake and afebrile with stable vitals except for high blood pressure $(202 / 112 \mathrm{mmHg})$. Glasgow Coma Scale (GCS) was 11, and the National Institutes of Health Stroke Scale (NIHSS) score was 26. The patient's face was asymmetric with unequal pupil reaction. There was right-sided hemiplegia with preserved left-sided motor and sensory functions. An initial unenhanced computed tomography (CT) of the brain was performed, which showed a large left middle cerebral artery (MCA) territory cortical and subcortical hypodensity suggestive of acute MCA infarction (Figure 1A and B). The cerebral CT-angiogram confirmed a total abrupt cut off at the left M1 segment of MCA (Figure 1C and D) with multiple filling defects in the left common carotid artery (Figure 2A-E).

Chest X-ray was not specific, and the ECG showed sinus rhythm. Blood tests revealed the presence of leukocytosis $\left(15.5 \times 10^{9} / \mathrm{L}\right)$ and elevated D-dimer levels $(17.09 \mathrm{mcg} / \mathrm{mL}$ FEU). The activated partial thromboplastin time (aPTT) was found to be low (26.6 seconds), while platelet counts, prothrombin time (PT), and INR were within normal limits. A tissue Plasminogen Activator (tPA) was not proposed due to late patient presentation. The Alberta stroke program early CT score (ASPECTS) was 3-4 as reviewed by a neuroradiologist; therefore, the patient was not considered a mechanical thrombectomy candidate. Therefore, the neurosurgery team was consulted and declared that there is no neurosurgical intervention, the patient was started on aspirin, atorvastatin and was eventually admitted to adult ICU with neuromonitoring, the next morning the swab came to be positive, and he was shifted to COVID-19 ICU. A follow-up CT brain scan was performed, which showed stable left MCA territory infarction with no midline shifting. On admission day 2 , the patient had a sudden drop in consciousness level. An urgent brain $\mathrm{CT}$ was ordered and showed further progression of the left MCA territory edema with new hemorrhagic components, causing midline shift and mass effect (Figure 1E).

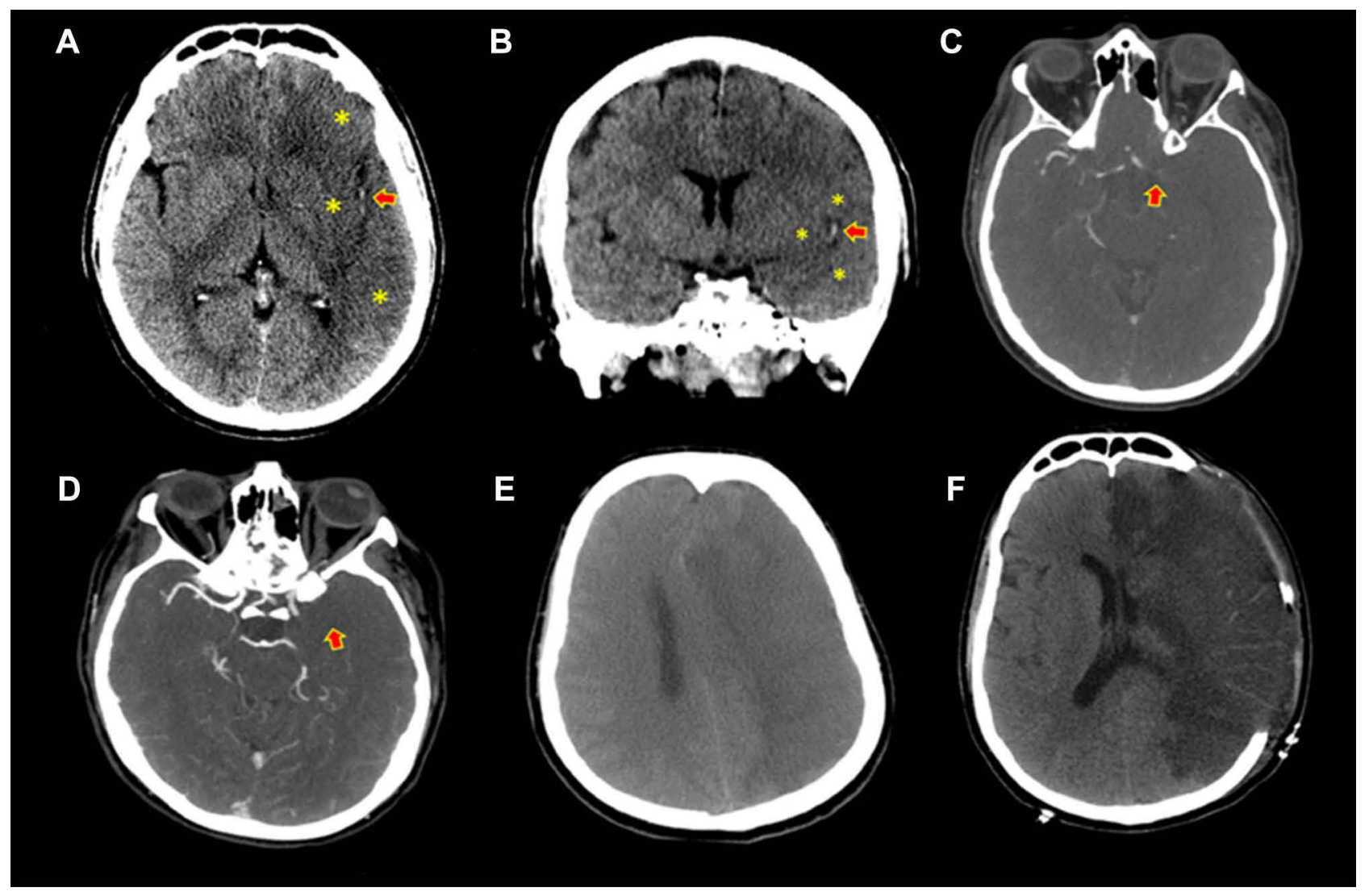

Figure I (A) Axial and (B) coronal images of the unenhanced computed tomography (CT) scan of the brain showed an acute left middle cerebral artery (MCA) infarction, which manifested as cortical and subcortical hypodensity with loss of gray-white matter differentiation and cortical swelling involving the left frontal, parietal, and temporal regions (asterisk); hyperdense MCA signs were also noted (arrow). (C) Axial and (D) axial maximum intensity projection (MIP) images of the CT angiogram of the brain showed complete occlusion of the left supraclinoid internal carotid artery and proximal MCA (arrows). (E) Brain CT demonstrated the presence of a malignant MCA infarction with hemorrhagic transformation, causing significant midline shifting and mass effect. (F) Postoperative CT. 


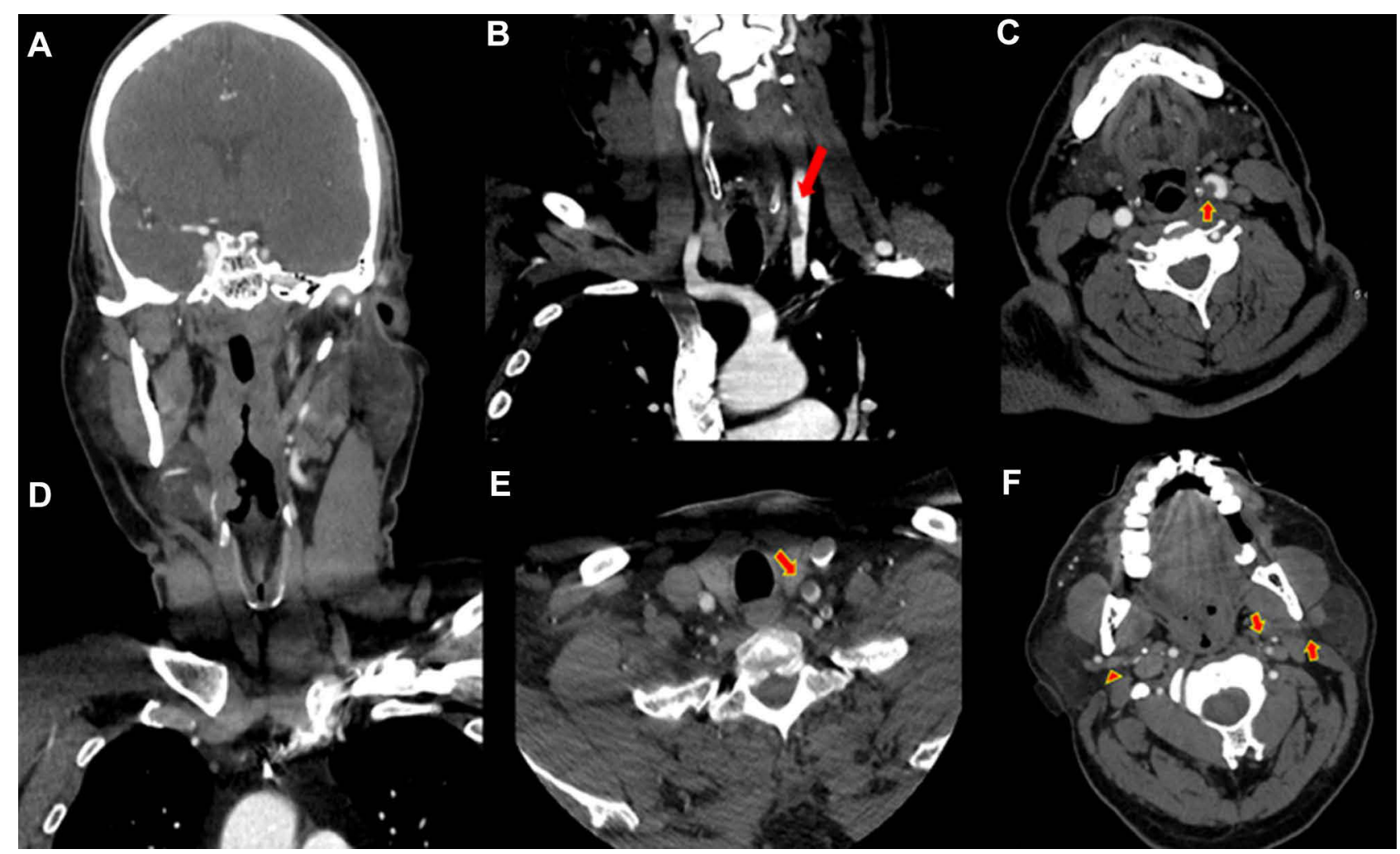

Figure 2 (A and B) coronal and (C and D) Axial images of the computed tomography (CT) angiogram of the neck showed multiple hypodense peripheral fungating filling defects within the left common carotid artery (arrows). (E) Axial imaging of the CT angiogram of the neck showed complete occlusion of the distal left external carotid artery and facial arteries (dotted arrows), compared with the normally opacified vessels on the right side (arrowhead).

Left craniotomy decompression was done by the neurosurgery team (Figure 1F), and antihypertensives were subsequently administered. A postoperative CT brain scan showed an improvement of the previous mass effect and further evolution of the large left MCA infarction. New left ACA infarction was seen as a complication of the previous subfalcine herniation or midline shift. One week later, the patient developed asystole and passed away.

\section{Discussion}

Since December 2019, COVID-19 has become a global pandemic with more than 2,800,000 deaths. ${ }^{1}$ SARS-CoV2 patients may have multiorgan involvement, such as acute kidney injury, myocarditis, and life-threatening conditions leading to death. ${ }^{5}$ Moreover, stroke was introduced to the literature as one of the main presentations for COVID-19 patients. $^{5,6}$

The possible pathophysiology behind developing a stroke in COVID-19 patients has also been explored recently by Wijeratne et al in a systematic review. ${ }^{7}$ The process starts with binding of SARS-CoV2 to angiotensinconverting enzyme 2 (ACE2) allows the virus to enter the host cell and starts recruitment of macrophages, neutrophils, and monocytes. ${ }^{8-10}$ Furthermore, excessive activation of innate immune system leads to disruption of bloodbrain barrier throughout endothelial dysfunction. ${ }^{11,12}$ Eventually, the inflammation in the brain will cause thromboembolism formation and acute stroke. ${ }^{7}$

Our case report described acute cerebral ischemia in an asymptomatic COVID-19 patient without stroke risk factors. To the best of our knowledge, no similar presentation has been reported yet. In the previous literature, Mao et al were first to highlight the acute ischemic stroke among COVID-19 patients, the study reported cerebrovascular insult among $5.7 \%$ of 88 patients with severe symptoms. ${ }^{6}$ Recently, a meta-analysis and systematic review on more than 100,000 COVID-19 patients found the incidence of stroke to be $1.4 \%$. Nannoni et al stated that more severe infection, having hypertension, diabetes mellitus, and coronary artery disease are the main risk factors for stroke. ${ }^{13}$ However, that might not be the case; hence, numerous authors reported stroke events after mild COVID-19 infection or no risk factor for cerebrovascular accident. $^{6,14,15}$ 
Managing stroke patients with COVID-19 is challenging; hence, patients may present with loss of consciousness, mental status alteration, speaking difficulty, while also being highly infectious. ${ }^{5,16}$

Moreover, the literature showed that the mortality rate of stroke patients is higher among those who are COVID-19 infected. ${ }^{13}$ For that reason, a temporary guideline was issued by the American Heart Association/American Stroke Association to clear the picture regarding stroke management in COVID-19 pandemic. ${ }^{17}$ Firstly, when a stroke patient presented to ED, a rapid assessment should be made to categorize the case into suspected/confirmed COVID-19 case or low-risk individual. Also, to do the swabbing and to extract the important labs. However, as mentioned earlier, many stroke patients will present with altered mental status which makes it more difficult to triage, and it is safer to keep a high index of suspicion among all patients and to use full COVID-19 precautions even if the patient is asymptomatic. ${ }^{18}$ After the initial assessment, the imaging is be preferred to be done within 20 minutes of arrival, and according to the patient's history, labs, and CT result, the management will be directed toward thrombolysis, mechanical thrombectomy or other supportive care. ${ }^{17}$

\section{Conclusions}

Acute ischemic strokes are one of the challenging complications of COVID-19 infection. Initial rapid assessment and management are crucial in optimizing the outcomes on these patients. Nevertheless, wearing appropriate PPE should be instituted while providing adequate care.

\section{Ethical Approval}

Institutional Review Board (IRB) was not required and written informed consent for publication of their details was obtained from the patient's next of kin.

\section{Acknowledgment}

College of Medicine Research Center, Deanship of Scientific Research, King Saud University

\section{Funding}

This research did not receive any specific grant from funding agencies in the public, commercial, or not-forprofit sectors.

\section{Disclosure}

The authors report no conflicts of interest in this work.

\section{References}

1. World Health Organization. COVID-19 weekly epidemiological update; April 6, 2021. Available from: https://www.who.int/publica tions/m/item/weekly-epidemiological-update-on-covid-19-6-april2021. Accessed April 7, 2021.

2. Han H, Yang L, Liu R, et al. Prominent changes in blood coagulation of patients with SARS-CoV-2 infection. Clin Chem Lab Med. 2020;58(7):1116-1120. doi:10.1515/cclm-2020-0188

3. Xie Y, Wang X, Yang P, Zhang S. COVID-19 complicated by acute pulmonary embolism. Radiol Cardiothorac Imaging. 2020;2(2): e200067. doi:10.1148/ryct.2020200067

4. Campbell CM, Kahwash R. Will complement inhibition be the new target in treating COVID-19-related systemic thrombosis? Circulation. 2020;141(22):1739-1741. doi:10.1161/CIRCULATIONAHA.120. 047419

5. Avula A, Nalleballe K, Narula N, et al. COVID-19 presenting as stroke. Brain Behav Immun. 2020;87:115-119. doi:10.1016/j. bbi.2020.04.077

6. Mao L, Jin H, Wang M, et al. Neurologic manifestations of hospitalized patients with coronavirus disease 2019 in Wuhan, China. JAMA Neurol. 2020;77(6):1-9. doi:10.1001/jamaneurol.2020.1127

7. Wijeratne T, Gillard Crewther S, Sales C, Karimi L. COVID-19 pathophysiology predicts that ischemic stroke occurrence is an expectation, not an exception-a systematic review. Front Neurol. 2021;11:1759. doi:10.3389/fneur.2020.607221

8. Basu S Hematological manifestations of COVID-19: from cytopenia to coagulopathy; 2020.

9. Soy M, Atagündüz P, Atagündüz I, Sucak GT. Hemophagocytic lymphohistiocytosis: a review inspired by the COVID-19 pandemic. Rheumatol Int. 2020:1-12.

10. Crayne CB, Albeituni S, Nichols KE, Cron RQ. The immunology of macrophage activation syndrome. Front Immunol. 2019;10:119. doi:10.3389/fimmu.2019.00119

11. Najjar S, Najjar A, Chong DJ, et al. Central nervous system complications associated with SARS-CoV-2 infection: integrative concepts of pathophysiology and case reports. $J$ Neuroinflammation. 2020;17 (1):1-14. doi:10.1186/s12974-020-01896-0

12. Spence JD, De Freitas GR, Pettigrew LC, et al. Mechanisms of stroke in COVID-19. Cerebrovasc Dis. 2020;49(4):451-458. doi:10.1159/ 000509581

13. Nannoni S, de Groot R, Bell S, Markus HS. Stroke in COVID-19: a systematic review and meta-analysis. Int $J$ Stroke. 2020;1747493020972922. doi:10.1177/17474993020972922

14. Viguier A, Delamarre L, Duplantier J, Olivot J-M, Bonneville F. Acute ischemic stroke complicating common carotid artery thrombosis during a severe COVID-19 infection. J Neuroradiol. 2020;47 (5):393-394. doi:10.1016/j.neurad.2020.04.003

15. Fara MG, Stein LK, Skliut M, Morgello S, Fifi JT, Dhamoon MS. Macrothrombosis and stroke in patients with mild Covid-19 infection. J Thromb Haemost. 2020;18(8):2031-2033. doi:10.1111/ jth. 14938

16. Gandhi M, Yokoe DS, Havlir DV. Asymptomatic transmission, the Achilles' heel of current strategies to control Covid-19. $N$ Engl J Med. 2020;382(22):2158-2160. doi:10.1056/NEJMe2009758

17. Leadership ASC. Temporary Emergency Guidance to US Stroke Centers During the Coronavirus Disease 2019 (COVID-19) Pandemic: on Behalf of the American Heart Association/American Stroke Association Stroke Council Leadership. Stroke. 2020;51 (6):1910-1912. doi:10.1161/STROKEAHA.120.030023

18. Ojo AS, Balogun SA, Idowu AO. Acute ischemic stroke in COVID-19: putative mechanisms, clinical characteristics, and management. Neurol Res Int. 2020;2020:1-7. doi:10.1155/2020/ 7397480 


\section{Publish your work in this journal}

The International Medical Case Reports Journal is an international, peer-reviewed open-access journal publishing original case reports from all medical specialties. Previously unpublished medical posters are also accepted relating to any area of clinical or preclinical science. Submissions should not normally exceed 2,000 words or 4

published pages including figures, diagrams and references. The manuscript management system is completely online and includes a very quick and fair peer-review system, which is all easy to use. Visit http://www.dovepress.com/testimonials.php to read real quotes from published authors. 